\title{
A parallel but not necessarily connectionist model of the auditory system
}

\author{
FREDERICK J. BREMNER \\ Trinity University, and Brooks School of Aerospace Medicine, San Antonio, Texas \\ MICHAEL YOST \\ Trinity University, San Antonio, Texas \\ and \\ LAUREN SULLIVAN \\ Brooks School of Aerospace Medicine, San Antonio, Texas
}

\begin{abstract}
The basic processing elements (the neurons) in the brain operate in the millisecond range and are about a million times slower than a computer (Feldman, 1985). In order to make up for this lack of computational speed, the brain must use a parallel multisynaptic method to transmit information. This paper presents a parallel processing model of the auditory system; the model accounts for the frequency and the sound-localization information.
\end{abstract}

The connectionists (Feldman, 1985; Feldman \& Ballard, 1982; Hinton \& Anderson, 1981) have presented a paradigm of information processing that takes into account the anatomy and physiology of the brain. This paradigm, named the connectionist model, uses the arrangement of neurons as part of its shared exemplar. In particular, the major premise of this model states that large amounts of information are not transmitted by individual neurons. Instead, the neurons are connected to a large number of other neurons that form a network (Feldman \& Ballard, 1982). It is the mosaic of the neurons in the network that contains the information.

Connectionists believe that the neurons in this network are in parallel because of the speed with which human information processing occurs. As an example, there are many latent steps that must take place before a sensory stimulus will reach a muscle and produce an observable response to the environment. First, the sense organs must be aroused; then, the nerves conduct the stimulus to the brain; and, finally, a signal is sent to the muscles. Only when this process is complete can the muscles react. In this model, most of the processing is done in the brain proper. The smallest number of neurons involved in this process is six. A chain of three neurons conducts the message to the brain, and a chain of three others conducts the message to the muscles. It is well known that the transmission time between neurons is approximately $1 \mathrm{msec}$ (Ruch \& Fulton, 1961). Nevertheless, even in a simple two-neuron knee-jerk reflex, there is a reaction time of about $40 \mathrm{msec}$. Certainly, this slow cycle time is due in part to a slow electromechanical output device (i.e., muscles and bones). However, the human brain can discrimi-

Please send reprint requests to Michael Yost, Office of the President, Trinity University, San Antonio, TX 78284. nate between two sensory stimuli almost as fast as the muscles can react. Those who agree with the connectionist theory have reasoned that since the brain is a fast psychological discriminator, despite the fact that it has a very slow basic cycle time, the neurons of the brain must process information in parallel.

To elaborate on the connectionist premise, let us consider other human reaction time data. In a simple reaction, in which a uniform stimulus is presented and a uniform response is required, there is a first-trial latency period of about $200-250 \mathrm{msec}$. In a two-choice situation, the reaction time measures about $300-350 \mathrm{msec}$ (Woodworth \& Schlosberg, 1956). The basic processing elements (the neurons) in the brain operate in the millisecond range and are about a million times slower than a computer (Feldman, 1985). To compensate for this lack of computational speed, the brain must use a parallel multisynaptic method to transmit information. This paper presents a parallel processing model of the auditory system. Although this model may be connectionist in nature, it is the parallel quality of the auditory system that is emphasized, and not the interneuronal relationships.

\section{ANATOMY}

The auditory model presented here is built on the anatomy of the basilar membrane and the hair cells. There are approximately 16,000 hair cells arranged in rows and columns between the basilar membrane and the tectorial membrane. There are about 3,500 hair cells arranged in a single column on the innerside of the rods of Corti. The 12,000 outer hair cells are arranged with at least four to a row, but as the helicotrema is approached the rows widen to 5 and then to 6 cells (Netter, 1983). The anatomical design of the basilar membrane aids in the detec- 
tion of frequency changes. The structure of this membrane alters gradually along its length toward the helicotrema. This allows selected groups (rows) of hair cells to respond readily at particular frequencies. Because of this frequency selectivity, the basilar membrane, or, more correctly, the hair cells, are said to be tonotopically organized (Lindsay \& Norman, 1977). In fact, the entire auditory system, from hair cells to the auditory cortex, is tonotopically organized (Rhode \& Smith, 1986a, 1986b). It has been estimated that there are 3,100-3,500 total rows of hair cells (Netter, 1983).

In addition to its tonotopical organization, the auditory system has two comparitors, the right and the left superior olivary nuclei (Van Bergeijk, 1962). In these nuclei, interactions take place between the signals arriving from the two ears. Depending on which ear hears the loudest signal, the olivary neurons react differently (Worden, Marsh, \& Bremner, 1966). This binaural code is then transmitted to the auditory cortex, where various cells respond to it (Reale \& Kettner, 1986).

\section{PHYSIOLOGY}

The most widely believed physiological theory of auditory functioning is the place theory (Dittrich, 1963) as modified by Békésy and Rosenblith (1951). The place theory suggests that the rows of hair cells are uniquely stimulated for each discriminable sound frequency and that the rows progressively change from the helicotrema to the oval window as the frequency is increased. The hair cells that respond send a coded message through the eighth cranial nerve to the auditory nuclei (Rose, Brugge, Anderson, \& Hind, 1968). The ability of the ear to sense changes in frequency can be measured by presenting pairs of tones to a subject, who must discriminate whether or not these tones have the same frequencies. The smallest difference in frequency a subject is able to discriminate is called the just noticeable difference (the JND) between the frequencies. It has been determined that there are 52 neurons per JND on the basilar membrane (Lindsay \& Norman, 1977). Extrapolating from these two values, we estimate that about 13 rows of hair cells would be involved in determining a frequency JND.

\section{NEUROPSYCHOLOGY}

There are many discriminations one can make with sound. In the following experiment, frequency, loudness, and location are the characteristics of the stimuli that are evaluated. This paper attempts to demonstrate the relationship between what happens in the nervous system (including the transducer cells) and what is psychologically perceived.

The frequency of sound is easily related to the musical scale. Each octave of a standard musical scale is exactly twice the frequency of the previous octave. There are 12 equally spaced notes within each octave. The note musicians use to tune their instruments is A4 (the A above mid- dle C). It has a frequency of $440 \mathrm{~Hz}$. The $\mathrm{A}$ above this note has a frequency of $880 \mathrm{~Hz}$. Likewise, the $A 3$ and A2 notes have frequencies of 220 and $110 \mathrm{~Hz}$, respectively. These four sounds are discriminable, since they are separated on the basilar membrane by more than 13 rows of hair cells (Lindsay \& Norman, 1977). This is a distance, and hence a frequency, that is larger than a JND.

\section{EXPERIMENTAL DESIGN}

\section{Subject}

The subject in this study is a human adult with "normal" hearing.

\section{Apparatus}

The apparatus is an IBM PC with a music program. The program includes tone stimuli at 110, 220,440, and $880 \mathrm{~Hz}$. Earphones, a chair for the subject, and a computer keyboard are arranged in an anechoic chamber. Eight computer keys are arranged in two sets of four so that one button in each set represents one of the four frequencies on each side. There also is a switching circuit and an attenuator to make one of the tones to one ear more intense (louder).

\section{Procedure}

The subject, wearing earphones, is seated in a chair. The four stimulus tones are presented simultaneously to each ear; one tone to one ear, however, is increased two JNDs in loudness. The JND for loudness was determined using the same procedure described for frequency JND above. The subject has the four fingers of the left hand on the V, C, X, and Z keys and the four fingers of the right hand on the $\mathrm{N}, \mathrm{M}$, comma, and period keys. When the complex four-tone stimulus is presented, the subject is instructed to press the button corresponding to the loudness tone on the side he/she perceives it to have occurred.

\section{Model}

Our model of the auditory system was built in a spreadsheet program on a personal computer. The format of the tables and explanation that follows uses a "row-andcolumn" spreadsheet notation. In Table 1, Column A represents the frequency of the incoming sounds, and Column B represents the output of the hair cells. Note that these cells have a theoretical magnitude. Column C represents a theoretical sensory memory buffer that holds information from Column B. Column D represents the superior olivary nucleus, otherwise known as the comparitor. Column $E$ represents the multiplexer and is a type of truth table. A 1 in Column E signifies the sound with the greatest loudness, and a 0 signifies the sounds that do not have the greatest loudness. The top half of Table 1 represents the left ear; the bottom half represents the right ear. The last line of Table 1 shows the equation for a specific column.

The equation at the bottom of Table 1 represents the operation of the transducer. It states that if the stimulus 
Table 1

Auditory System Model (Transducer Equation)

\begin{tabular}{|c|c|c|c|c|}
\hline $\begin{array}{c}\text { A } \\
\text { Frequency }\end{array}$ & $\begin{array}{c}\text { B } \\
\text { Transducer } \\
\text { Output }\end{array}$ & $\begin{array}{c}\text { C } \\
\text { Sensor } \\
\text { Buffer }\end{array}$ & $\begin{array}{c}\text { D } \\
\text { Comparitor }\end{array}$ & $\underset{\text { Multiplexer }}{\mathrm{E}}$ \\
\hline \multicolumn{5}{|c|}{ Left Ear } \\
\hline 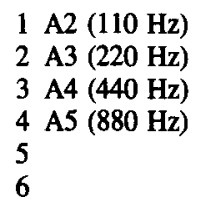 & $\begin{array}{r}20.0 \\
52.0 \\
60.0 \\
7.0\end{array}$ & $\begin{array}{r}20.0 \\
52.0 \\
60.0 \\
7.0\end{array}$ & $\begin{array}{r}\text { Left Comp. } \\
66\end{array}$ & $\begin{array}{l}0 \\
0 \\
0 \\
0\end{array}$ \\
\hline \multicolumn{5}{|c|}{ Right Ear } \\
\hline $\begin{array}{r}9 \text { A2 }(110 \mathrm{~Hz}) \\
10 \text { A3 }(220 \mathrm{~Hz}) \\
11 \text { A4 }(440 \mathrm{~Hz}) \\
12 \text { A5 }(880 \mathrm{~Hz}) \\
13 \\
14\end{array}$ & $\begin{array}{r}22.0 \\
57.2 \\
66.0 \\
9.0\end{array}$ & $\begin{array}{r}22.0 \\
57.2 \\
66.0 \\
9.0\end{array}$ & Right Comp. & $\begin{array}{l}0 \\
0 \\
1 \\
0\end{array}$ \\
\hline
\end{tabular}

Table 2

Auditory System Model (Comparitor Equation)

\begin{tabular}{|c|c|c|c|c|}
\hline $\begin{array}{c}\text { A } \\
\text { Frequency }\end{array}$ & $\begin{array}{c}\text { B } \\
\text { Transducer } \\
\text { Output }\end{array}$ & $\begin{array}{c}\text { C } \\
\text { Sensor } \\
\text { Buffer } \\
\end{array}$ & $\begin{array}{c}\mathrm{D} \\
\text { Comparitor }\end{array}$ & $\begin{array}{c}\mathrm{E} \\
\text { Multiplexer }\end{array}$ \\
\hline \multicolumn{5}{|c|}{ Left Ear } \\
\hline $\begin{array}{ll}1 & \text { A2 }(110 \mathrm{~Hz}) \\
2 & \text { A3 } \\
(220 \mathrm{~Hz}) \\
3 & \text { A4 }(440 \mathrm{~Hz}) \\
4 & \text { A5 }(880 \mathrm{~Hz}) \\
5 & \\
6 & \end{array}$ & $\begin{array}{r}20.0 \\
52.0 \\
60.0 \\
7.0\end{array}$ & $\begin{array}{r}20.0 \\
52.0 \\
60.0 \\
7.0\end{array}$ & $\begin{array}{r}\text { Left Comp. } \\
66\end{array}$ & $\begin{array}{l}0 \\
0 \\
0 \\
0\end{array}$ \\
\hline
\end{tabular}

\begin{tabular}{rrrrr} 
& \multicolumn{3}{c}{ Right Ear } & \\
9 A2 $(110 \mathrm{~Hz})$ & 22.0 & 22.0 & 0 \\
$10 \mathrm{~A} 3(220 \mathrm{~Hz})$ & 57.2 & 57.2 & & 0 \\
11 A4 $(440 \mathrm{~Hz})$ & 66.0 & 66.0 & 1 \\
12 A5 $(880 \mathrm{~Hz})$ & 9.0 & 9.0 & Right Comp. & 0 \\
13 & & & 66 & \\
14 & & & \\
\hline &
\end{tabular}

intensity at the left ear is larger than 10 (the threshold value), the value coming in from the right side of the ear will be multiplied by 1.1 . However, if the intensity at the left ear is smaller than 10 , the value 9 will be printed.

The equation for the operation of the comparitor (Column D) appears at the bottom of Table 2. The largest intensity value from Column $\mathrm{C}$ is searched for and is then printed in Column $\mathrm{D}$. The equation for the operation of the multiplexer (Column E) appears at the bottom of Table 3. The number in Cell D5 is compared with every number in Column $\mathrm{C}$. For any number in Column $\mathrm{C}$ that is smaller than the value in Cell D5, a zero is printed in Column E. However, for any number in Column $\mathrm{C}$ that is larger than the number in Cell D5, a 1 is printed. In this example of the model, the incoming sounds are always from the right side. In a real situation, the sounds could come from either side, and all three of the equations would be operating in a simultaneous sequence.

\section{DISCUSSION}

This is a working model of the auditory system. It simulates the ability of the ear to discriminate between the loudness, frequency, and location of a sound. The results show the amazing ability that humans have to perform complex signal analysis in only a few hundred milliseconds. As Davis (1951) pointed out, all the information from the ear must pass through the bottleneck of the auditory nerve in order to get to the brain. Therefore, the challenge of any simulation of the auditory system is to transmit all of the information contained in this code.

The number of variables of this code are few. They consist of the: (1) particular fiber fired (place theory and tonotopic organization); (2) frequency of firing (maximum $1000 \mathrm{~Hz}$, probably only $800 \mathrm{~Hz}$ ); (3) patterning of firing within a single fiber; (4) number of fibers firing (volley theory, parallel processing); (5) pattern of firing in multiple fibers; and (6) number of fibers synapsing on any given cell (spatial summation, connectionist theory). With these variables, the system codes sound intensity, frequency, location, and quality. It is the purpose of our research to simulate the parallel nature of the auditory system in coding the variables presented above. In particular, the neural messages of frequency intensity and location are carried on a nonindependent set of parallel lines. Frequency in this model is designated by the particular line stimulated (tonotopic organization). The parallel nature of the auditory system is shown by multiple frequency signals traveling in parallel lines (the rows in our model). However, we simply assigned an intensity value to each frequency line. The best estimate is that as the intensity of a stimulus increases, the number of parallel lines recruited by that frequency increases. This intensity feature could be added to our model with very little overhead. Finally the location of sound by our model was accomplished by a type of software comparitor. Our

Table 3 Auditory System Model (Multiplexer Equation)

\begin{tabular}{|c|c|c|c|c|}
\hline $\begin{array}{c}\text { A } \\
\text { Frequency }\end{array}$ & $\begin{array}{c}\text { B } \\
\text { Transducer } \\
\text { Output }\end{array}$ & $\begin{array}{c}\text { C } \\
\text { Sensor } \\
\text { Buffer } \\
\end{array}$ & $\begin{array}{c}\text { D } \\
\text { Comparitor }\end{array}$ & $\begin{array}{c}\text { E } \\
\text { Multiplexer }\end{array}$ \\
\hline \multicolumn{5}{|c|}{ Left Ear } \\
\hline $\begin{array}{ll}1 & \text { A2 }(110 \mathrm{~Hz}) \\
2 & \text { A3 }(220 \mathrm{~Hz}) \\
3 & \text { A4 }(440 \mathrm{~Hz}) \\
4 & \text { A5 }(880 \mathrm{~Hz}) \\
5 & \\
6 & \end{array}$ & $\begin{array}{r}20.0 \\
52.0 \\
60.0 \\
7.0\end{array}$ & $\begin{array}{r}20.0 \\
52.0 \\
60.0 \\
7.0\end{array}$ & $\begin{array}{r}\text { Left Comp. } \\
66\end{array}$ & $\begin{array}{l}0 \\
0 \\
0 \\
0\end{array}$ \\
\hline
\end{tabular}

\begin{tabular}{rrrrr} 
& \multicolumn{3}{c}{ Right Ear } & \\
9 A2 $(110 \mathrm{~Hz})$ & 22.0 & 22.0 & & 0 \\
$10 \mathrm{~A} 3(220 \mathrm{~Hz})$ & 57.2 & 57.2 & & 0 \\
11 A4 (440 Hz) & 66.0 & 66.0 & & 1 \\
12 A5 (880 Hz) & 9.0 & 9.0 & Right Comp. & 0 \\
13 & & & 66 & \\
14 & & & & \\
\hline
\end{tabular}

E1: (Value) @IF(D5 $>\mathrm{C} 1,0, \mathrm{C} 1 / \mathrm{C} 1)$ 
comparitor had to find the maximum intensity and to develop the truth table. In reality, this process occurs in parallel in the auditory system. Why the system has two comparitors (one right and one left) we do not fully understand, and we also do not fully understand why the two comparitors use opposite logic. That is, it is apparent that one comparitor uses "or" gates, whereas the contralateral side uses "nor" gates. Although we did not reverse the logic of the two comparitors, it would not be difficult to do so. The simulation presented here uses three variables to demonstrate a plausible mechanism for discriminating frequency, loudness, and location for a sound stimulus.

\section{REFERENCES}

BÉKÉSY, G., \& VoN RosenBlith, W. A. (1951). In S. S. Stevens (Ed.), Handbook of experimental psychology. New York: Wiley.

DAvis, H. (1951). Psychophysiology of hearing and deafness. In S. S Stevens (Ed.)., Handbook of experimental psychology. New York: Wiley.

DITTRICH, F. L. (1963). Biophysics of the ear. Springfield, IL: Thomas Feldman, J. A. (1985). Connectionists. BYTE, 10(4), 265-273.

Feldman, J. A., \& Ballard, D. H. (1982). Connectionist models and their properties. Cognitive Science, 6, 205-245.
Hinton, G. E., \& Anderson, J. A. (Eds.). (1981). Parallel models of associative memory. Hillsdale, NJ: Erlbaum.

LiNDSAY, P. A., \& NoRMAN, D. A. (1977). Human information processing (2nd ed.). New York: Academic Press.

NETTER, F. H. (Ed.). (1983). The CIBA collection of medical illustrations (Vol. 1). New York: CIBA Pharmaceutical Co.

REALE, R. A., \& KeTtNeR, R. E. (1986). Topography of binaural organization in primary auditory cortex of the cat: Effects of changing interaural intensity. Journal of Neurophysiology, 56, 663-683.

RHoDe, W. S., \& SMITH, P. H. (1986a). Encoding timing and intensity in the ventral cochlear nucleus of the cat. Journal of Neurophysiology, 56, 261-286.

Rhode, W. S., \& SMITH, P. H. (1986b). Physiological studies on neurons in the dorsal cochlear nucleus of cat. Journal of Neurophysiology, 56, 285-307.

Rose, J. E., Brugge, J. F., Anderson, D. J., \& Hind, J. E. (1968). Patterns of activity in single auditory nerve fibers of the squirrel monkey. In A. V. S. De Reuck \& J. Knight (Eds.), Cell differentiation, a CIBA Symposium. London: Churchill.

Ruch, T. C., \& Fulton, J. F. (Eds.). (1961). Neuropsychology. Philadelphia, PA: Sanders.

VAN BERGEIJK, W. A. (1962). Variation on a theme of Békésy: A model of binaural interaction. Journal of the Acoustical Society of America, 34, 1431-1437.

WOODWORTH, R. S., \& SCHLOSBERG, H. (1956). Experimental psychology (rev. ed.) New York: Holt.

Worden, F. G., Marsh, J. T., \& Bremner, F. J. (1966). Electrophysiological analogue of the "time-intensity" trade. Journal of the Acoustical Society of America, 39, 1089-1099. 